\title{
May the real ubuntu please stand up?
}

\author{
Nyasha Mboti \\ University of Johannesburg
}

\begin{abstract}
This article defends an alternative account of ubuntu, and makes a novel proposition about African morality and ethics. In doing so, it refutes the normative account of ubuntu premised on the aphorism umuntu ngumuntu ngabantu (persons are persons through other persons). According to this "greatest harmony" account, Africans are harmonic collectivists and sharers, linked together by community-defining conveyor-belts of moral and ethical goodwill "gifts". It is assumed that an African theory of right action produces harmony and reduces discord. I aver, however, that such a prima facie interpretation, notwithstanding its intuitive appeal, is still open to some rather strong doubt.
\end{abstract}


“...but everyone’s different”.

Andrey Bolkonsky to Pierre Bezukhov (Leo Tolstoy, War and Peace, 1868-9(2006), p.413).

"...men and women are searchers and their ontological vocation is humanization...."

(Paulo Freire, 1970 [2005], p.74).

\section{INTRODUCTION}

This article demonstrates that conventional accounts of ubuntu, illustrated in translations and interpretations of the aphorism umuntu ngumuntu ngabantu (persons are persons through other persons), are significantly doubtful. A strong foretaste of this doubtful position is provided in Augustine Shutte's (2001) pioneering work, Ubuntu: An ethic for a new South Africa. Such rendering is, of course, by no means limited to Shutte's work. As the article will show, several other important contemporary definitions of $u b u n t u$ that preceded and succeeded Shutte's monograph have by and large failed to adequately question what appear to be illogical interpretations of umuntu ngumuntu ngabantu and its variations. Instead, these definitions have continuously, and perhaps conveniently, strengthened and added to this interpretation in their own varied ways.

These definitions continue to assert that Africans are, a priori, ethically, morally and humanely dependent on each other. The definitions hold that an action is right to the extent that it maximizes harmony. I will call these "the greatest harmony" accounts. From these accounts it follows that discord reduces ubuntu. I will call this "the greatest harmony principle". That is, harmony is isolated as the principle which approves or disapproves of every action whatsoever. This article demonstrates why, by and large, these definitions fail. On the whole, definitions of $u b u n t u$ have remained consistently and purposely fuzzy. Inadequate and inconsistent conceptualization has partly helped to perpetuate the admittedly 
otiose view that classical African ethics have no conception of "individual freedom" and that the conception of "freedom" is a European import.

\section{SETTING THE SCENE}

Gade (2011) has studied the evolution of the notion of ubuntu over a period of 165 years. He demonstrates that the term "ubuntu" has appeared in writing since at least 1846. Importantly, Gade analyses the definitional changes that the term has undergone in written sources between 1846 and 2011. Particularly telling is Gade's observation that the aphorism umuntu ngumuntu ngabantu was used for the first time to describe ubuntu in the period between 1993 and 1995. That is, this use is actually quite recent. Subsequently, a preferential consensus of sorts grew and accreted around the application of the aphorism. As Gade (2011) notes, "Most authors today refer to the proverb when describing $u b u n t u$, irrespective of whether they consider ubuntu to be a human quality, African humanism, a philosophy, an ethic, or a worldview" (p.303).

I aver that the preferred reading of umuntu ngumuntu ngabantu since 1993 is, in fact, hegemonic. I am obviously drawing narrowly on the definition of hegemony popularized by Italian thinker Antonio Gramsci in the Prison Notebooks (1971). Gramsci (1971) regarded hegemony as a kind of "prestigious" moral and intellectual leadership predicated on "educative pressure" and majoritarian consent (p.242). On the one hand, my reading of Gramsci tempts me to regard umuntu ngumuntu ngabantu - in the custodial hands of ubuntu scholars and theorists writing since the 1990 s - as a particular kind of "superstructure". This is obviously a reference to how umuntu ngumuntu ngabantu gradually became an institutionalized idea or prestigious way of seeing spread through "educative" and other pressures. Shutte's preoccupation with an ethic for the "new" South Africa suggests that one source of pressure was political. 
On the other hand, the scholars and theorists of ubuntu - due to their narrow adherence to, and influence over, a specific reading of ubuntu as umuntu ngumuntu ngabantu - constitute what Gramsci referred to as a "fundamental group" or "civil society". It is this "civil society" of ubuntu scholars that is behind the "prestigious" adoption and spread of the particular "superstructural" translation, interpretation and definition of $u b u n t u$ as "a person is a person through other persons". The hegemonic use of umuntu ngumuntu ngabantu as a catch-all distillation of ubuntu has resulted in a more or less widespread uniformity of definition. Such uniformity reflects, on the one hand, the prestige and confidence in which extant definitions are held and, on the other hand, a general state of inadequate rigour in attempts to define $u b u n t u$.

Though in this article I focus sustained attention on a single account of ubuntu (Shutte, 2001), one that more or less represents the prestigious definition of ubuntu and exemplifies the problems of theorizing it, ubuntu (or its variants) has in fact been the subject of a number of attempted definitions (Samkange \& Samkange, 1980; Menkiti, 1984;

Broodryk, 2002; Bujo, 2001; Gyekye, 1987; Mokgoro, 1998; Masolo, 2004; Ramose, 1999 \& 2003; Tangwa, 1996; Verhoef \& Michel, 1997; Wiredu, 1996; Enslin \& Horsthemke, 2004; Cornell \& van Marle, 2005; Metz, 2007 \& 2011; Metz \& Gaie, 2010; Mokgoro \& Woolman, 2012; Bamford, 2007; Praeg, 2008; Letseka, 2012; Cornell, 2011, 2012). The settled definition of choice seems to always return, again and again, to the saying "umuntu ngumuntu ngabantu" (in Nguni languages), "motho ke motho ka batho" (in Sotho languages), "a person is a person through other persons" (in English), and so on. Other variations such as "I am because we are" are also advanced.

A much quoted definition of ubuntu is credited to Desmond Tutu (1999):

When we want to give high praise to someone we say, "Yu, u nobuntu"; "Hey, soand-so has ubuntu." Then you are generous, you are hospitable, you are friendly 
and caring and compassionate. You share what you have. It is to say, "My humanity is caught up, is inextricably bound up in yours." (emphasis added) (p.31).

Tutu's definition is important because it encapsulates what all the other definitions share: that ubuntu is about a dependent (kind of) humanity. I have deliberately emphasized the words "caught up", "inextricably" and "bound up in yours" to show the superstructural pervasiveness of the linked-chain, conveyor-belt metaphor. The adverb "inextricably" means that something is so joined, webbed and entangled as to make escape impossible. There is an inescapable assumption of fate. Harmony is thus cast as some sort of categorical imperative. African morality and ethics are inconceivable without it. This, in general outline, is the "greatest harmony" account. Such an account prescribes harmony as a universal rule of action governing the moral lives of Africans.

As I shall further establish, this specifically authorised script or template has gradually but surely settled in discourses about $u b u n t u$. Such a script-template fixes $u b u n t u$ to the normative Tutu-ist formula described above: Africans as extraordinary communitarians and harmony-bound collectivists dependent on each other's good-will. An illustration of this pervasive script is located in the work of, among others, eminent philosopher-theorists of ubuntu such as Mogobe Ramose (1999) and Thad Metz (2007). This "superstructural” script adheres to a specific normative and succinct account of $u b u n t u$ that explains how persons, particularly Africans, achieve meaningful, ethical and full humanity. Humanity, so asserts this elegant account, is given to a person by and through other persons. That is, humanity is a good-will gift.

Of course, there are problems from the onset. For instance, one particularly knotty problem with positing the good-will and harmony thesis is that it is impossible to find anything that everybody agrees is definitive of harmony and good-will. To solve this problem, two interconnected things happen: Firstly, intellectual footwork is necessary. This 
partly involves one-sided appeals to intuition. Secondly, universals are postulated. Such universals, as we will see, are sign-posted by the use of the pronoun all and adverb only. The assumption is made that the only account of morality, ethics and humanity that all Africans mutually recognise is $u b u n t u$. The superstructural script is thus invested with finding ways of defining, and, indeed, of not defining ubuntu. As will be established in the section below, both the definition and the not-definition bring us no closer to answering the question: may the real ubuntu please stand up?

For the real ubuntu to stand up, at least one precondition must be satisfied. This is that we cannot see what we want only. As an example, let us assume a scenario involving two actions, one seemingly "right" (or highly visible) and the other seemingly "wrong" (or highly private and hidden): eating and excretion. It is fair to say that though we may drool with appreciation when eating pleasant food, we wince and think "yuck" while producing excreta. But should the fact that we publicly appreciate eating while relegating all signs of excretion to "unseen" spheres mean that eating is more "right" compared to excretion? Though we may not ordinarily think much of excreta while we are eating, its relationship to the mouth is actually absolutely essential.

Basically, the act of eating is one with the act of excretion, such that we would not eat if we did not excrete and, similarly, would not excrete if we did not eat. Not only is excretion as important as eating and a person's anus as important as their mouth, but take away one and the other becomes meaningless. I extend this scenario to ethics, where I am of the view that it is objectively wrong to limit "right action" only to what is intuitively appealing to the exclusion of that which has empirical warrant. If eating is right action, so is excretion. The force of this objection will become clearer in the next sections. 


\section{(Not) Defining ubuntu}

Ramose's (1999) ubuntu project is based on the stated aim to present "African philosophy from within" (p.iv) and to establish "research proposals on African philosophy based on ubuntu" (p.iv). To this end, he states that:

Ubuntu is the root of African philosophy. The be-ing of an African in the universe is inseparably anchored upon ubuntu. Similarly, the African tree of knowledge stems from $u b u n t u$ with which it is connected indivisibly. Ubuntu then is the wellspring flowing with African ontology and epistemology. ... African philosophy has long been established in and through ubuntu (Ramose, 1999, p.49).

In other words, if one were to "find" ubuntu, or at least to define it, they would have inevitably located the ground of African ontology and epistemology. In a sense, this encapsulates the project that all ubuntu scholars are involved in: finding the real ubuntu. Ramose, in stating that "Ubuntu is the root of African philosophy" and that "ubu-ntu" (sic) is the fundamental ontological and epistemological category in the African thought of Bantuspeaking people" suggests that he has already found the map to this Promised Land.

Where Tutu above used the adverb "inextricably" to show that there is no escape for Africans from the "greatest harmony" principle, Ramose uses "indivisibly" and “inseparably". Indivisibly means that a thing's parts are incapable of being broken up. Inseparably extends the definition to say that a thing's parts are incapable of being regarded separately. These adverbs do not merely tweak the meaning of ubuntu. Rather, they function as intensifiers. They amplify the function and place of "the greatest harmony" principle in African ethics, giving additional emotional context to the notion of $u b u n t u$. But what does this forcefulness give rise to? What does it elide? Whatever the answer, it seems that the tendency of these adverbs is to increase the sense of fated-ness within African ethics. At the 
same time, they remain vacuous fillers that do not say exactly what is "inextricable", "indivisible" or "inseparable" about ubuntu, or why.

Ramose's definition of ubuntu is that it is "rheomodic", "holonistic" and "pantareic".

This jargon, it appears, is really a way of saying that ubuntu is difficult to define or, at least, to fix. For Ramose, any definition of ubuntu must acknowledge that the word itself is a portmanteau. Acknowledging the two-words-in-one, Ramose says, is the first step to acknowledging that the word somehow contains traces of both an African ontology and an African epistemology. Hence:

Ubuntu is actually two words in one. It consists of the prefix $u b u$-and the stem $n t u$-. Ubu- evokes the idea of be-ing in general. It is enfolded be-ing before it manifests itself in the concrete form or mode of existence of a particular entity. $U b u$ - as enfolded be-ing is always oriented towards unfoldement, that is, incessant continual concrete manifestation through particular forms and modes of being. [...] $u b u$ - is always oriented towards $n t u$-. At the ontological level, there is no strict and literal separation and division between $u b u$ - and $n t u$-. Ubu- and $n t u$ are not two radically separate and irreconcilably opposed realities. On the contrary, they are mutually founding in the sense that that are two aspects of being as a one-ness and an indivisible whole-ness. $U b u$ - as the generalised understanding of be-ing may be said to be distinctly ontological, whereas $-n t u$ as the nodal point at which be-ing assumes concrete form or a mode of being in the process of continual unfoldment may be said to be the distinctly epistemological.... Accordingly, Ubu-ntu then not only describes a condition of be-ing, insofar as it is indissolubly linked to umuntu, but it is also the recognition of be-ing becoming and not, we wish to emphasise, be-ing and becoming (Ramose, 1999, p.52).

This lengthy definition, again, ironically performs the function of a caution against definition. In summary, however, Ramose has defined ubuntu - vaguely still - as “one-ness", "wholeness" and "being-becoming". This is also the meaning of "rheomodic", "holonistic" and "pantareic". One-ness, whole-ness and be-ing becoming, as they are here deployed, reflect the concern, simultaneously, with the "connectedness" and "becoming-ness" of African persons. 
The radical expectation that ubuntu "is the root of African philosophy", that it "is the fundamental ontological and epistemological category in the African thought of Bantuspeaking people" and that it encapsulates the "one-ness", "whole-ness" and "be-ing becoming" of Africans is typical of the tendency towards generalization that attends the definitional aspect within $u b u n t u$ scholarship. That is, definitions turn out - perhaps purposely and conveniently - to be as imprecise as possible. In this way, if ubuntu were a bag, it would be a magical bag without a bottom. Such a bag can carry just about anything that is put into it, without ever filling up. The problem with this magical bag is that the longer it takes to fill up, the further it postpones the task of defining its object. The longer the postponement, the closer we get to eventually abandoning the project altogether.

Ramose's claim of a one-size-fits-all bag of ubuntu falls short, firstly, of decisively saying what "interdependence" really is and, secondly, of addressing the complex sociality and social intimacy of Africans. It is true that the lives of Africans everywhere are entangled. But in what way are such entanglements objective proof of interdependence? Should we not be persuaded, rather, that such entanglements are definitive proof of historical nestedness that we are related through history? Not only is it not obvious that Africans are correspondingly adapted to be interdependent, but the nature of the interdependencies (or linkages, or pathways) in the ubuntu "web" are far from clear. Only the opacity remains.

The bottomless bag definition is thus in one sense a vague and limited representation of actual reality, able to show only a tiny portion of the complexity of real African persons. It appears that always, when we speak about ubuntu, we are - perhaps necessarily simplifying, aggregating and generalising. This disclaimer needs to attend most examinations of ubuntu. The identification of a moral and ethical pattern or norm that is common to all Africans is always already fraught with dangers. This broad lumping says little of the messy material flux of actual life. 
One important departure from this bottomless magical bag methodology is demonstrated in Thad Metz's work. In philosophical terms, Metz's specific aim has been to define $u b u n t u$ as precisely, attractively and elegantly as possible. For instance, Metz's (2007) important breakdown of ubuntu into six conceptions shows that all "six distinct theories" of ubuntu are alike in regarding $u b u n t u$ as a quality hardwired with notions of social, human, communal and collective good. Metz's (2007) attempt to codify ubuntu as precisely as possible develops in the following statement:

An action is right just insofar as it promotes shared identity among people grounded on good-will; an act is wrong to the extent that it fails to do so and tends to encourage the opposites of division and ill-will (p.338).

In this statement, shared identity grounded on good-will is ranged against division and illwill. Right is right just insofar as it promotes the conveyor-belt of good-will. Wrong is wrong to the extent that it fails to convey good-will and harmonized living.

The construction of shared identity grounded on good-will ranged against division and ill-will is based on Metz's distinguishing of two different sorts of harmony. The first is "shared identity". Hence:

Families, clubs, churches, schools, firms and nations are instances of shared identity. The greater the common sense of self: the more people think of themselves in terms of their group membership; the more ends they share; the higher they rank these ends; the more they share the same reasons for adopting these ends; and the more they will sacrifice to achieve these ends. The opposite of shared identity is division, a matter of defining oneself in opposition to others, others defining themselves in opposition to one, and one adopting ends that conflict with those of others. Enemies on a battlefield are clearly divided in this way (Metz, 2007, p.335).

In this account, shared identity collocates rather well with a common sense of self, group membership, shared ends, and shared reasons. The impact word here is "share". An absence 
of sharing immediately voids, indeed obliterates, identity. Metz, however, does not find "shared identity" to be "very morally important in itself". He favors a second "different sort of harmony, one more worth promoting from a moral point of view". This he qualifies as "good-will". Good-will is taken to refer to "a certain caring or supportive relationship" (Metz, 2007, p.336). Hence:

One has a relationship of good-will insofar as one: wishes another person well (conation); believes that another person is worthy of help (cognition); aims to help another person (intention); acts so as to help another person (volition); acts for the other's sake (motivation); and, finally, feels good upon the knowledge that another person has benefited and feels bad upon learning she has been harmed (affection) (Metz, 2007, p.336).

Wishing another well, recognizing the need to help them, aiming to help them, acting to help them, acting on their behalf, and empathy, are identified as being some of the distinctive qualities of good-will. In this account, ubuntu is, therefore, specifically defined as a shared identity grounded on good-will. That is, shared identity and goodwill are paired together, as if in a semantic prosody. Such a pairing has obvious appeal; it adds precision and elegance to the definition of ubuntu.

However, in this convenient pairing of shared identity and good-will only good-will is identified as being morally significant. This is because a shared identity may not be based on the six conditions of good-will noted above. Metz gives the example of the apartheid era National Party that may have had a shared identity but without the good-will. Specifically, the six conditions of good-will bring about the "pro-attitude". Metz illustrates and defines what, in his view, may constitute good-will:

Examples of good-will include nursing, teaching and charity work. The greater the good-will, the stronger the desire that others benefit, the firmer the belief they are worthy of it, the higher the ranking of one's end of helping others, the larger the sacrifice on others' behalf, and the greater the empathy with their flourishing 
or injury. The opposite, ill-will, would consist of outright sadism and Schadenfreude (Metz, 2007, p.336).

A point worthy of further remark is the use, in this quotation, of the adjectives "greater", "higher" and "larger". These words signify an increase in the humanity of the actors such that the greater the good-will the profounder the humanity. However, the increase signifies much more. "Greater", "higher" and "larger" reflect an incessant movement from less to more. This movement will be instructive in our consideration, below, of the specific nature of the conveyor-belt of good-will.

Metz considers that "the most attractive sort of harmonious relationship to promote" is one that includes both good-will and shared identity (Metz 2007, p.337). He deems the combination of the two conditions to be the most attractive conception of harmony, defined as a broad sense of "love." Hence, a "loving relationship" constitutes "a prima facie attractive moral value" (p.337). Placing basic moral status in a loving relationship between people is hence construed to be more holistic. Metz thus moves from shared identity to good-will, to a combination of shared identity and goodwill and, finally, to love as markers of an intuitively satisfying and uncontroversial African moral theory. In sum, argues Metz, the most justified normative (and distinctively African) theory of right action produces harmony and reduces discord.

Metz's work on ubuntu displays several layers of complexity and clearly attempts to apply a rigorous operational and interpretive framework upon the definition of $u b u n t u$. There is something intuitively appealing in the normative "greatest harmony" account of ubuntu. Unfortunately, this very intuitive appeal is precisely the source of the problem. The force of my objection lies in the fact that our intuitions are hardly that reliable in the business of informing us about what actions are conceivable and why. To decide what is conceivable and what is not, we need more than simply appeal to intuitions. 
The normative "greatest harmony" account attempts to elevate harmony to a moral duty that Africans must simply uphold. That is, harmony is constituted as some form of categorical imperative. But is disharmony really that inconceivable? Is good-will really neutral? There is, for me, a clear difficulty in elevating of harmony to a moral duty that Africans must simply uphold. Not only does such an account lack any real empirical warrant, but it is never obviously true that harmony is categorically imperative; it also does not seem implausible that disharmony is as conceivable as harmony, and is also somehow hardwired with harmony. Reliance on intuitions is unlikely to extricate us from what we shall regard below as the problem of the see saw. What is needed, in part, is a counter-intuitive, contextual, and less universalising move.

It is clear that we should be moving towards even more complexity as opposed to generality and simple schemes. If such an intuitively appealing, elegant norm such as the "greatest harmony principle" existed, it would mean that ethical relationships among Africans could be generally predicted, and precisely too. But it is not clear why we should limit our definition to only that which can be classified in this way. For instance, Africans - and all human beings in general - compete and cooperate in equal measure. Cooperation, however, does not stop because we compete, and competition is not obliterated by cooperation; one is not complete without the other. Both combat and friendship are ethically necessary. There is, it seems, partly a suggestion that the problem is in the deficiency of our classifications and categories. In truth, Africans are not restricted - and need not be restricted - to any one moral code. Rather, it seems that we are always already a multi-ethic people, involved in complex multi-ethic interactions with others dependent on context.

The final production of harmony and reduction of discord in Metz's account, in particular, are instructive. Production of harmony is inextricably tied to reduction of discord, and vice versa. That is, one is a function of the other. However, it is not clear if harmony is 
produced through reducing discord, and if discord is reduced through producing harmony. If this is the case, then this particular theory of right action works algorithmically, like a seesaw. As production of harmony goes up, discord is reduced. Any increase in discord, on the other hand, lowers the harmony. The problem with this see saw, however, is that it does not quite clarify right action. Rather, it seems to clarify the dependence of right action on wrong action, and wrong action on right action. In another sense, the see saw merely clarifies "action", shorn of its moral clarity. Just as the electric eel kills using the same electric current that it uses to defend itself - such that the method for attacking is the same for defending harmony and discord may belong to the same category of moral current. Both harm and cooperation, harmony and discord can result from social relationships.

This reading, if correct, would contradict accounts that interpret umuntu ngumuntu ngabantu solely in terms of good-will. Instead, there is renewed scope to see umuntu ngumuntu ngabantu as referencing a messier, undisciplined relationship between persons. Such a relationship between persons can be broken and fractious, or harmonious and pleasing. However, neither a broken nor harmonious relationships should be seen as being better than the other. Both are. Both are not. Here, I am positing an equivalence. Firstly, there is value in regarding a broken relationship as being authentically human as much as a harmonious relationship.

Secondly, a broken relationship can be as ethically desirable as a harmonious one. For instance, freedom follows from a break from oppression. Finally, harmonious relations can be as oppressive and false as disharmonious ones. For instance, the cowboy and his horse are in a harmonious relationship. John Wayne, however, is still an ectoparasite; the commensal relationship between him and his horse not only suggests that the cowboy is a phoretic type, but also that not all is as it seems. At the very least, both harm and cooperation can result from such social relationships. 
I argue that positing this sort of isotropic equivalence allows us to study ethics (and morality) not as norms helping us to distinguish right action from wrong but, rather, as the study of salient collisions of the two. When the two collide, dispersal, scattering and superposition happen. When the two collide within a kind of posited isotropy of space where all directions in space are equal - the result is a rich account of African ethics. Ethics is hence the critical appreciation (as opposed to suppression) of the behaviour, power, significance, salience and reach of these collisions and obstructions. It is plausible, for instance, that cooperation and mutualism among Africans is voluntary, not obligatory. At least, there are more aspects to it than just what is ordinarily assumed. We depend on each other, yes, but do we have to? I think we depend on each other but do not have to. Just because we depend on each other does not mean that we are obliged to depend on each other.

The selective privileged reading of umuntu ngumuntu ngabantu as more or less exclusively approximating good-will is distracting. It focuses our attention on only one side of Africans: the good side. It fails to see how the good side is completely superposed with, refracted by, and even empirically unrecognizable from, the bad side. That is, the ethical refracts the unethical, and the unethical diffracts the ethical. In African societies, what does the (so-called) good collide with? What disperses it? Is it history? Is it love, or economics, or poverty, or non-governmental organizations, or mass media, or technology, or race, or civil society, or police batons, or teargas, or God, or sexuality? Is it all of these singly or all at once? Some and not others? None of the above? Surely, all these questions, and many others besides, would need to be adequately and sufficiently answered first before one assumes what an African morality or African ethics is.

It would appear to me, therefore, that in human relationships, as such, the unethical is as salient as the ethical, such that the two disrupt and construct one another in the true fashion of a turnstile or revolving door. At least, seeing the relationship between the two as being 
inherently messy rewards attention. Good-will is not like sound, which travels rectilinearly. Rather, normal human relations cause ethics to bend, reflect, diffract, refract, scatter and travel in several directions, sometimes all at once. These directions are not always pleasant, nor always desired. In fact, daily life is lived in the knowledge that collision and dispersal are more or less the only constants. "Harmony", in such contexts, is treated with as much suspicion as endless strife. In the end, life never really settles into total harmony or total discord, complete good-will or complete ill-will. Rather, it is nearly always halfway (or quarter-way or two-thirds) between the two, in an im/perfect balance. African ethics is therefore best regarded as a tertium quid.

It follows that moral and ethical laws always march in step to the reality of collisions, obstructions and dispersals. This is easily seen in routine African proverbs that apply only in some contexts and not in others. For instance, mwana asingachemi anofira mumbereko (the unprotesting child dies in its mother's carry cot) directly contradicts mugoti unopihwa anyerere (the juicy reward is given to the unprotesting child). The first saying does not render the second one nonsense. Rather, it pushes it into the foreground. The lesson both sayings contain is that life throws people all kinds of curveballs. Some curveballs require people not to protest. Other curveballs, however, lead to outright protest. Right action, by definition, is hence knowing which is which. Wrong action, by extension, is not knowing which is which. Both silence and protest, in this case, result in pleasing, satisfying reward for those who know what action is "right" or "wrong" in each given context.

To protest when one should keep quiet, or keep quiet when one should protest, is thus completely lacking in good-will, particularly as experience would have taught people that such action leads to unhappiness in the community. Good-will is here some sort of halfbrother to good sense. Good-sense, for its own part, is next to good citizenship. Good citizenship, on the other hand, makes for ethical living. Good citizenship, then, is what is 
expected to keep society from completely falling into the hands of context-illiterate idiots, toadies, tyrants, fools and sociopaths. That is, it is not right action to protest when one should keep quiet, or keep quiet when one should protest. Right action, like truth, is therefore bivalent. The question could be asked: but how does one know when to protest or keep quiet?

There are at least two answers: the first is that, as Bob Marley sang, who feels it knows it. A Nigerian friend who is confined to a wheel-chair once showed me a building - at a university where both of us were doing our postdoctoral fellowships - that had a wheelchair ramp from the outside that led to a flight of stairs. I was surprised because I had not noticed, and in all likelihood would never have noticed, that anomaly. She told me that it is quite normal, in fact, for her to notice (and keep a record) of buildings that have stairs and no lifts. "Who feels it knows it" is thus a reference to the sum of blind-spots that we inherit particularly from realities we do not live. That is, it is up to the hungry child or the child in the carry cot to decide when an action is right.

Normally, "society" (a term for anyone who bears witness to an action) would then praise the child for demonstrating good sense in having known exactly when to act. Knowing when to act is equal to knowing how to act. As noted, good sense is next to good citizenship, and good citizenship makes for ethical living. In reality, society is really praising the child for showing a great degree of individual freedom - what we would normally call independence (of thought and action). Leaving the decision to the child is therefore not to abandon ethical living to a naïve relativism. Rather, it is a principal demonstration of authentic ethical humanism.

The second answer is that it is, in fact, not a question of when to protest or keep silent at all, but rather, how to protest or keep silent. That is, both protesting and keeping silent are part of the same isotropic and bivalent continuum of "right" actions, based on good sense and good citizenship. Looked at even more closely, silence is protest and protesting is silence. At 
least, this is what an ethics of collision should teach us. An African person, who has lived in Africa long enough to appreciate its quotidian realities, has enough good sense to know that an action is right insofar as it allows one to make an informed choice whether to speak or remain silent. Right action is, thus, the transitive demonstration of critical, informed choice in context. Hence:

An action is right just insofar as it maximally promotes informed choice grounded on context; an act is wrong to the extent that it fails to do so and tends to block informed choice.

It is quite possible that ubuntu is really just another word for "good citizenship" for African persons, an (impure) ethics of good citizenship based on independent thought and action, individual freedom, critical good sense, and informed choice in context. The mistake of arbitrarily separating human actions from the context and continua to which they belong is, as we may have seen, at the heart of the narrow interpretation of ubuntu.

I would go further to argue that it is a narrow Cartesianism that insists on seeing protest and silence as opposites or as never-touching, asymptotic dualities. The rightness of an action is thus far more complex than is allowed for in the limiting prescription of ubuntu as good-will suffused umuntu ngumuntu ngabantu. As part of this account of an African ethics of collision, I propose that the messier the relationship between persons, the more freedom and agency the individual has to shape their relationship with others in ways that increasingly suit and benefit each individual involved in the relationship.

In sum, Metz's general position regarding what is intuitively true and pleasing, attractive and elegant in African ethics is well-founded. However, we make a grave mistake if we test morality and ethics through intuitions alone. Here, an example is necessary. As a food lover, I shall return to the part-scatological, gastro-related example of food and excreta that was applied earlier. As displeasing as we may find the smells (and sometimes the discomfort) 
that attend the act of excretion, and the intuitively unsightly detritus that exits our bodies, it is an empirical fact that we would not be able to eat if we did not excrete. I am hence justified in seeing eating and excreting as constituting the very same state(s) of affairs. The importance of considering the problem of ethics from a "states of affairs" position is that it helps us to appreciate how the strength of something is not necessarily diminished by a failure to appeal to our (always limited) intuitions.

The fact that we may not intuitively recall that the exit point of food as it leaves our bodies is as important as its entry point does not at all justify a diminishing of the former's value. Both are openings to our bodies. In order to do justice to the question of what produces right action, we may need to consistently recognise that there are other, equally important realities that produce right action, whether or not we intuitively regard them as producing right action. Right action, as such, is not limited to what we putatively regard as right or as important. Rather, it goes beyond intuitions. In fact, it may be that we actually need to start moving away from what we regard as right or good to considering what we do not ordinarily regard as right or good. This implies, in particular, a closer than normal study of the sum of our ethical blind spots.

I argue, hence, that matters of morality and ethics are partly best spoken about by considering full states of affairs or contexts. As shown in our example, the "pleasing" act of eating exists in a continuum, a full state of affairs, with the "yuck" act of passing faeces. In the end, so-called right action is to so-called wrong action what the mouth is to the anus. In this sense, Metz's account of ubuntu is too intuitive, or at least appeals to intuition too closely. Its preferential focus on the elegant and the attractive (the quality tasty bits of ubuntu) is ultimately detrimental to the detritus of ubuntu. Is an ubuntu that eats but does not excrete possible? 


\section{Ubuntu: a Gift?}

Shutte's (2001) monograph, Ubuntu: An ethic for a new South Africa, is a pioneering attempt to codify an interpretive framework both for thinking about ubuntu and for applying it to the "new South Africa". Intending the book to be about ethics, or "a study of values that people try to live by" (p.2), his larger task was to show "how this essentially communitarian idea can be reconciled with the idea of individual freedom that is central to European ethical thought" (emphasis added) (p.viii). Shutte intended to demonstrate "how traditional African ideas can be combined with others from the authentic European humanist tradition to form an ethic of UBUNTU for a new South Africa" (p.33). For Shutte, "the concept" of ubuntu embodied an understanding "of what it is to be human and what is necessary for human beings to grow and find fulfilment”. Ubuntu was to be categorized as an ethical concept that expressed "a vision of what is valuable and worthwhile in life" (p.2). At the centre of ubuntu was "the idea that umuntu ngumuntu ngabantu, persons depend on persons to be persons" (p.3).

Shutte's project to find a universal "ethic" capable of "overcoming the great division in the world today" and repairing the divisions in South Africa created by apartheid led him to posit an invented division between the "African" and the "European" ethical tradition. Of the "two ideas" on which he based his book ("freedom and community" respectively), one represented "the glory of the history and culture of Europe" while the other was "the soul of Africa" (p.11). Not only is each of these ideas allotted a chapter each, but, ultimately it is on this arbitrary binary that the whole discourse of an ethic for the new South Africa turns.

The African ethical tradition is constructed as having at least four core features. Firstly, the conception of ubuntu is said to have originated from a "pre-literate, pre-scientific, pre-industrial" culture (p.9). In this regard, Shutte insists that his reference point is "traditional African ideals rather than contemporary ones." The relevant African ethical 
traditions of interest were those that pre-existed "the influence of European culture" (p.16).

Secondly, the African "way of looking at humanity is not materialist" (p.8). Not being

materialist meant having no attachment to "science and technology" and avoiding "the

mistakes of contemporary scientific and technological culture" (p.8). In essence, the African

ethical tradition was opposed to "materialism and dualism, and individualism and

collectivism" (p.8). Thirdly, the African self is "outside the body, present and open to all"

(emphasis in original) (p.22).

Fourthly, and most importantly, in the African ethical conception persons depended on persons to be persons. It was only by "belonging to the community that we become ourselves" (p.9). Some of the markers of this fourth feature were community indabas where “consensus" prevailed (p.28) and, above all, the extended family (p.29). The extended family, Shutte speculates, is "probably the most common, and also the most fundamental, expression of the African idea of community" (p.29). Hence:

The idea of community is the heart of traditional African thinking about humanity. It is summed up in the expression umuntu ngumuntu ngabantu, a person is a person through persons. This means that a person depends on personal relations with others to exercise, develop and fulfill those capacities that make one a person. At the beginning of one's life one is only potentially a person. One's life, if all goes well, is a continual becoming more of a person through one's interaction with others. Personhood comes as a gift from other persons (Shutte, 2001, p.12).

The "key insight in the African idea of persons", therefore, was that "persons exist only in relation to other persons" (emphasis added) (p.23). It is to the fourth feature of the African ethical tradition that we shall return in our discussion of the problem of the "gift".

The fourth feature of the African ethical tradition - umuntu ngumuntu ngabantu - is the subject of the chapter titled "The African Vision". In a section titled "The conception of community", Shutte reiterates that: 
the key insight that is the foundation of the ethics of UBUNTU...is the insight that persons depend on persons to become persons, umuntu ngumuntu ngabantu. It is this insight that gives the African conception of community its distinctive character (Shutte, 2001, p.25).

In other words, it is on the fourth feature that the whole African ethical tradition is assumed to rest. Africans are held to have "discovered" a unique conception of community which was devoid of the "discovery" of "individual freedom". The discovery of individual freedom was uniquely limited to Europeans. The abundance of "community" and the lack of "individuality" among Africans consequently led Shutte to suggest that an ethic for the new South Africa would result only from a combination or marrying of the two ethical traditions.

The third chapter of Shutte's book is dedicated to outlining the "The European Discovery". This "discovery" emerges from a "European culture" that he assumes taught the world "to see the self as something private, hidden within our bodies" (emphasis in original) (p.22). Whereas the African tradition discovered "community", the European tradition was based on "the discovery...of individual freedom" (p.34). Individual freedom was purportedly discovered in Europe over a period of three thousand years during which the "profound and powerful idea that human beings are free" was recorded "for us to read and reflect on" (p.34). Hence:

The idea of freedom, as it has been developed over the centuries in the history of Europe, is that when we deliberately choose to do something we have judged worthwhile, we are self-determining, free from being completely influenced by causes other than ourselves (Shutte, 2001, p.11).

The "idea of freedom" is hence the "way of understanding persons, as subjects who are aware of themselves in all they think or do, and who cause themselves to think and act" (p.46). This way of understanding human freedom, argues Shutte, is at the centre of European thinking 
and not only marks the summit of the modern European insight into human freedom (p.46) but also "the glory of European thought" (p.50).

In fact, the "idea of freedom" is judged to be "probably the most far-reaching and world-changing discovery of all" (p.34). It is also judged to be "certainly the most important" for the universal discussion of ethics. The conclusion is that Africans did not and could not have "discovered" individual freedom. Even if they had somehow done so, they could not have achieved such a feat by themselves. Hopefully, the account that I have defended above of the two children - goes some way to putting to bed this incredibly otiose and unphilosophical view that regards African ethics as having no independent conception of individual freedom. Such a view is, in every sense, beyond the pale.

As part of outlining the new ethic of $u b u n t u$, Shutte makes a key conceptual invention: that "personhood is a gift" (p.25). Hence he argues that at the beginning of life one is "really not a person at all" (p.24). Personhood "is not something already there at the beginning of a person's life" (p.25). Rather, it only "comes to me from others as a gift". A striking statement is that "If it is not given, it cannot be acquired" (p.25). Hence ubuntu is "the name of the acquired quality of humanity that is the characteristic of a fully developed person and the community with others that results" (emphasis added) (p.31). The "gifted" nature of ubuntu is emphasized by the use of the word "only" to represent the fate-like, inescapable nature of the "gift". Hence:

- (Humans exist) "only as part of the different relationships that bind us to others" (Shutte, 2001, p.12).

- ...the key insight in the African idea of persons: persons exist only in relation to other persons (Shutte, 2001, p.23).

- The human self...only exists in relationships to its surroundings; these relationships are what it is (Shutte, 2001, p.23). 
The use of "only" fixes umuntu ngumuntu ngabantu" to what seems to me to be an excoriating finality: either you are in community with others or you are banished from humanity. This is what is implied by the phrase "achieving a common mind and heart" (p.29) and by the suggestion that the "deepest moral obligation" for Africans is to become more fully human by "entering more and more deeply into community with others" (emphasis added) (p.30).

To be sure, Shutte is not the first or only scholar of $u b u n t u$ to fix Africans to an untenable finality. Others, such as Menkiti (1984) and Ramose (1999) have given more or less similar accounts of immutability. Menkiti (1984) for instance, argues that:

...persons become persons only after a process of incorporation. Without incorporation into this or that community, individuals are considered to be mere danglers to whom description "person" does not fully apply. For personhood is something which has to be achieved, and is not given simply because one is born of human seed (emphasis added) (p.172).

The assertion that human beings are mere "danglers", before their so-called incorporation into full humanity or personhood, is an extreme exfoliation of Shutte's notion of gift. Where Shutte says that the gift is "acquired", Menkiti states that the gift must be "achieved". It is not expressly clear, however, how that “achievement" exactly happens. In Menkiti's view, it is not in doubt that in the "African view of man...man is defined by reference to the environing community" (p.171), that "as far as Africans are concerned, the reality of the communal world takes precedence over the reality of individual life histories, whatever these may be" (p.172) and that it is "in rootedness in an ongoing community that the individual also comes to know himself as a durable, more or less permanent fact of this world" (p.172). The meanings of "environing community", "reality of the communal world", "rootedness", “ongoing community" and "durable, more or less permanent fact of this world", however, remain worryingly fuzzy and unexplained. 
Ramose (1999) argues, even more forcefully than Menkiti and Shutte, that "personhood, from whatever angle you look at it, is to be acquired in terms of traditional African thought" (emphasis added) (p.81). Obviously, Ramose's choice of words is uncannily close to Shutte's:

In order to be a person the human individual must, according to traditional African thought, go through various community prescribed stages, and be part of certain ceremonies and rituals. Only at the completion of all prescribed stages does the human individual acquire the status of a person. Prior to this the individual is regarded as "it" to show that he or she is not yet incorporated into the body of persons. In traditional African thought personhood is, therefore, acquired and not merely established by virtue of the fact of being human. (emphasis added) (Ramose, 1999, p.1).

Not only is the "status of a person" withheld until such a time that "incorporation" happens, but the human being is not a person at all but an "it"! Praeg (2008) calls these descriptions "radical statements of ontological interdependence" (emphasis in original) (p.372). Ubuntu he refers to as a "philosophy of interdependence" (emphasis in original) (p.372). The notion of interdependence notably clarifies and updates the account of the gift and the conveyor belt of good-will.

The untenability of Shutte's (2001) (and Menkiti's and Ramose's and Metz's, among others) view of ubuntu largely lies in the fact that it turns Africans into danglers, its, shells and non-persons. This is because this notion of $u b u n t u$ conceives humanity as a gift, given by other persons. In Shutte's exact words, ubuntu "comes to me from others as a gift. If it is not given, it cannot be acquired" (Shutte, 2001, p.25). The problem with this view of ubuntu is that it turns on illogicality: if $u b u n t u$ is not given, it cannot be acquired. This assumption is illogical not only because it presupposes the existence of an originary giver, ${ }^{2}$ who started all the gifting in the first place, but also the existence of a conveyor belt of shared, passed-on gifts. Such an account, however, is patently unconvincing. This is because the starting point of such a conveyor belt is, in reality, impossible to conceive. 
Faced with an illogical starting point, this account can only solve the question of where, when and how the giving begins, and who begins the giving, by ultimately reducing the "gift" to a warrantless figure of speech. The problem is that the postulation of a figure of speech leaves the humanity of Africans in a sterile void and state of eternal abeyance. How can a non-human thing - a figure of speech - be the source of actual ethical, moral and human(e) attributes? In the absence of a convincing answer to this question, the ubuntu of umuntu ngumuntu ngabantu becomes a chimera. In turn, the voiding of umuntu ngumuntu ngabantu nullifies the debate about the nature of African ethics. Even more important, the critical question about what ubuntu really is is not only left unanswered, but abandoned.

What follows Shutte's account of the ethical gift is the ready conclusion that ubuntu is, to all intents and purposes, shared, collective and harmonic. At least, the rhetoric and metaphor of the gift figures prominently in this account. Such a notion of ubuntu rests on a specific interpretation of the umuntu ngumuntu ngabantu to mean that Africans are harmonic collectivists and sharers, linked together by community-defining conveyor-belts of moral and ethical transactions. Such an interpretation has a lot going for it. In addition to elegance and explanatory power, it (seemingly) favors Africans. Africans, historically maligned as terra nullius by Westerners, are for once favored as fully ethical and moral beings.

Such favor, however, is won at the cost of suppressing alternative accounts that demonstrate that African persons do not exclusively or even normally derive "rights", "freedoms" and "ethics" from the community or from the West. Strictly speaking, the word "community" does not even occur in languages such as Shona and Zulu. As will be iterated in the last two sections below, an alternative account of African "ethics" and "freedom" is not far off down the road. To get there, however, a number of propositional blockages need to be cleared and set aside. Once these are set aside, the little problem of a context-literate African ethics will hopefully be set up in full relief. 


\section{Some implications for "freedom" and "ethics"}

Shutte (2001) advances two sets of arguments that have a bearing on the question of "rights" and "freedom". The first is the contention that "the more one depends on community in a certain way, the freer one is" (emphasis in original) (p.13). The point is that Africans enter "freedom" and are able to express themselves more freely only after entering into dependent and contingent relationships with other Africans. A paradox is posited: the more bound and unfree Africans are, the freer they are. I regard the paradox and the sense of absoluteness encoded in the use of the adverb "only" to be - respectively - illogical and unfairly totalizing. What if this normative view is completely wrong? What if African persons want to reserve to themselves the right to be "free" with or without, and because of or despite, being in community with other Africans?

Further questions arise. Why should freedom only be subject to this one form of "gift"? Substantially: what do Africans want? Who can claim to know, decisively, what Africans want? What gives Africans - a people marked by the complexity, richness and profundity of their differences - peace, happiness and satisfaction? What if Africans simply want to live alongside other Africans and not through them? If ubuntu were merely a ladder or a metric unit of "dependencies" and 'interdependencies", what use would it be in the maelstrom of real life? Suppose some African persons withheld their "gifts" from others. Would that, then, be the end of freedom? Indeed, would that be the end of morality? These questions cannot be answered by simple appeal to "gifts" that are acquired only when given.

The second argument that Shutte advances is that "individual freedom" is the true source of "all rights and responsibilities in the culture produced by science and secularization in modern Europe" (emphasis added) (p.50). In fact, the "European discovery" of "freedom" is cited as being the very same one that "led to the idea of fundamental human rights 
possessed by all people" and, not surprisingly, "which all authorities, religious or political, had to respect" (emphasis added) (p.44). The totalizing use of the adjective "all" is calculated to leave no question as to who originated individual freedom. Shutte's account of the genealogy of "freedom" openly associates all accounts of "freedom" and "rights" with that same "freedom" that was "discovered" in the course of three thousand years of European history. $^{3}$

A clear, rigid distinction is drawn between two kinds of freedom: the freedom sourced from Europe, which is "individual freedom" and that from Africa, which is inherently interdependent. In essence, just as the codifiable European discovery was individual freedom, the codifiable African discovery is that of persons bound together in a state of complete ethical and moral (inter)dependence. One does not need to be a certified logician to see the flawed logic that exclusively associates "individual" freedom with the West and "interdependent" freedom with Africa. Such logic is made possible by what could only be described as long-settled sets of "overratings", "underratings", "overestimations" and "underestimations": overrating Western individualism; underestimating African individuality; overrating African interdependence; and underestimating Western interdependence.

The overrating of African interdependence, along with its close neighbor, underestimation of African individuality, is succinctly confirmed by African scholars such as Menkiti (1984) and Ramose (1999). Menkiti (1984), as noted earlier, regards Africans before “incorporation” into interdependence as mere “danglers”. In Ramose’s (1999) view, too, there is a difference between the "holonistic and the individualistic (derivative) conceptions" of a person. The area of difference is that "the holonistic" accords primacy to wholeness while "the individualistic" emphasizes individualism and accords primacy to it (p.79). In holonistic African traditional thought, therefore, the emphasis is supposedly on "the primacy of the greater environing wholeness over that of human individuality" (Ramose, 1999, p.80) 
such that "human individuality is a necessary but not sufficient condition for being a person" $\left(\right.$ p.81). ${ }^{4}$

I am wary, though, of the rigid dualities that Ramose adopts, particularly that of the "holonistic" versus “individualistic (derivative)". That is, I neither consider the two to be necessarily mutually exclusive nor do I see any value in seeing Africans as necessarily belonging to either of the two categories. What if Africans belong to neither category? Why should the limits of our categorising also be the limits of the ethical worlds of Africans? In truth, there is no limit to the categories one can posit, nor to the memberships one can hold in these groups. Memberships can be multiple, composite, ever-changing. It is not expressly clear, anyway, why one needs to clarify the problem through categories at all, or at least sorely through categories.

As may be noted, it seems rather convenient for Ramose to dismiss arguments that do not place Africans in the normative "greatest harmony" category as exceptional outliers (see footnote 4). By and large, what appears to be missing in these prevailing accounts of ubuntu by Shutte, Menkiti, Ramose and others is a strong preoccupation with seeing African persons as complex, expressive and subjective doing beings whose actions are never easily reducible to the limiting duality of "individual freedom" versus "interdependent freedom" or to producing harmony and reducing discord.

Shutte's later writings apparently exhibit more nuanced positioning. In the essay "African ethics in a globalising world", for instance, Shutte (2008) draws on contemporary Thomist philosophers in order to effectively talk up the notion of the "intersubjective transaction". In this account, people have a kind of "freedom-in-dependence" (p.26) which, at the same time, is careful to avoid rigid "collectivism". The notion of "intersubjective relationships between persons" (p.25) has, in this instance, been preferred in place of "gift". Ironically, however, the notion of intersubjective transaction has the effect of expressing the 
account of the gift and of "interdependent freedom", even more strongly - but without calling it by that name. Hence, in this upgraded account, "human life only exists by being shared" (emphasis added) (p.28). In particular:

The traditional African idea of community seems to accord very closely with the understanding of human nature in contemporary Thomist philosophy... which also avoids individualism by insisting on our dependence on other persons for our development. (Shutte, 2008, p.28).

Subtly retained, here, is the account of chronic "interdependence". Shutte adds that "it is only in strictly intersubjective relationships with others that we are able to grow as people" (emphasis added). The "intersubjective transaction", in particular, is the marker of such immutable interdependence. It is not difficult to sense that even this upgraded account of ubuntu is inherently intrusive, and therefore uncharitable. Retained, again, is the absolutizing use of "only" and the enduring distinction between the inherently "individual" freedom of Europeans and the inherently "interdependent" freedom of Africans.

Earlier, I made reference to the problem of the ethical see saw. As we saw, the see saw fails to completely clarify or define right action. What it seems to clarify is the dependence of right action on wrong action, and wrong action on right action. Such a reading contradicted the definition of $u b u n t u$ that is preferred solely in rectilinear terms of shared good-will. Instead, I argued, there is renewed scope to see ubuntu as referencing a messier, undisciplined relationship between persons. Relationships between persons that are broken and fractious, or harmonious and pleasing, are neither better nor worse than the other. That is, I posited an isotropic equivalence which would allow us to imagine instances where broken relationships are as authentically human and humanizing as much as harmonious relationships, broken relationships as ethically desirable as harmonious ones, and harmonious 
relations as potentially oppressive and false as a disharmonious ones. Central to my account of ubuntu is the discourse of bivalent collisions and dispersions.

For instance, the relationship of collision between freedom and oppression is such that freedom cannot be seen in isolation from its bivalent context. That context is, of course, oppression. In the same sense, the context of justice is injustice, and that of humanization is dehumanization. Positing one brings up the other. The bivalence, or dual-exchange relationship, of these opposites, therefore, requires that the notion of context be given prominence. Basically, freedom cannot be spoken about out of context. So does ethics and morality. African ethics are a function of African contexts. Such contexts, moreover, are inseparable from history and the supervening realities of everyday life. It is in these context that freedom and un-freedom, broken relationships and harmonious ones, and the un/ethical, should be seen. As an African who has lived all his thirty-odd year life on the continent, and who knows no other home, I suspect that life in Africa never really settles into total harmony or total discord. Rather, it is always halfway between the two. This "balance" is the most "harmonious".

The example I gave earlier - partly to query the normative account of $u b u n t u$ as harmonious - was that of horse and rider. The harmonious relationship between a cowboy and his trusty steed, for instance, is ultimately contingent on the continued silence of the horse. How precise, attractive and elegant can our definitions of John Wayne's horse's silence be? Who can properly decide what constitutes "right action" for the horse? How far down the road of "interdependence" can we get if we somehow got "Banner" (or "Dollar", or "Duke" or "Starlight" or "Dollor" or "Alamo") to talk about its feelings for its rider? Would the horse characterize their relationship - to borrow from biological notions of symbiosis - as commensal, ammensal or phoresy? In a phoretic relationship, it seems, Wayne would be 
described as the phoront, one who depends on his host, Banner, for transport from place to place without physiological dependence on each other.

Would "Banner" be unjustified to go further and characterize Wayne as a biotrophic parasite? Biotrophic parasites, such as ticks, depend on the survival of their host. The tick example actually would suggest biotrophic parasitism is an extremely successful mode of life. John Wayne on foot would not have survived a day in the Hollywood-imagined Wild West. He depended on his horse, which he also fed, watered and groomed. Beyond this, however, we will never know what his horse thought about the quality of their relationship. We will never know the horse's conception of freedom, or whether it had a conception of freedom at all. We would never know, that is, until Banner breaks its silence. But how does a horse break its silence? Because a horse cannot speak, there is no proper solution except to accept the world as it is: there will always be horses, riders, and horse-riding.

The only other solution I can see is to dismiss this horse-rider story as anthropomorphic, as clarifying nothing. Surprisingly, such "interdependent" relations are staple in the world of living persons. In particular, Africans have had to contend with more than three hundred years of a variety of riders, mostly white (and European) but increasingly also African. Surely, an ethics of horse riding needs to deal with the mechanics of horse silence (or neighing?). It is generally difficult to tell from the horse's silence, however, what it thinks about the ethics of the rider and of being ridden, whether or not horses have a morality and an ethics at all, and what these moral-ethics are. It is even more difficult to objectively tell, sorely on the basis of the horse's assumed silence, what horses want.

Finally, it is not possible to tell from the horse silence what interdependence means. If we extend the example from biology, we will note how parasites' relationship with their host, often referred to as symbiosis, is itself a form of "living together". This is despite the fact that parasites habitually reduce the fitness of their hosts. In the type of "living together" known as 
synnecrosis, both species are harmed by the interaction between them, and soon die out; necrotrophic relations involve the parasite killing the host, while the parasite survives; biotrophs do not want their host to die, otherwise they will die too. It is clear that each form of interdependence carries its own meanings. Interdependence, as an event, is not selfevident. Neither can it go without saying.

In light of these complexities of symbiosis, how exactly does ubuntu define its own form of interdependence? Are Africans interdependent because they are fated to be interdependent? Do they choose to be interdependent? Do they need to choose? Who "gifts" interdependence? What forms of interdependence are there? Indeed, who defines such interdependence and why? Is such definition neutral and value-free? What is its politics? Are we "right" because we intended, all along, to be "right"? Are we intentionally good? How much of "right action" is incidental, accidental and messy and how much is known, predictable, observable and measurable? Does it matter, anyway? These are knotty questions. The normative conception of ubuntu is, in my view, too loosely intuitive to address or even to prompt these sorts of questions.

It must be obviously recognized, I think, that the elegance and attractiveness of our propositions about the so-called "individual" nature of the freedom in European persons, on the one hand, and the "interdependent" freedom of African persons, on the other hand, is significantly contingent on a certain amount of (mutually allowed) silence(s). Africans, one thinks, do reserve the right to be silent in the face of an amazing amount of unsolicited pronouncements about their in-born tendency towards interdependence (or horse-ness). But until we unravel the nature of this silence - what this silence is, what it is about, what causes it, and what it causes - we cannot be sure what African or European morality or ethics is, or what $u b u n t u$ is. The real ubuntu will not stand up. Who can definitively say, really, what African ethics are or are not? 


\section{By Way of Conclusion}

This article has argued that the "greatest harmony" account of ubuntu that conceives of humanity as a gift, given by other persons, is untenable. Such an either/or outbound/inbound notion traps Africans in an intrusive ethical vicious circle. It must be replaced by one that recognizes and acknowledges that every African is different, and hence that Africans are persons with or without community. I argue that positing this sort of isotropic equivalence allows us to study ethics and morality not as norms helping us to distinguish right action from wrong but, rather, as the study of salient collisions of the two. Ethics and morality are no longer constituted in the rectilinear study of uni-dual distinctions of right/wrong and good/bad but, rather, the deepened appreciation of these collisions. The selective privileged reading of umuntu ngumuntu ngabantu as approximating interdependent and harmonious good-will obscures how right/wrong and good/bad are completely superposed.

The account of $u b u n t u$ that is clarified by the "greatest harmony" principle is solidly premised on "harmony". Harmony, notably, refers to a relationship characterized by agreement and lack of conflict; a pleasing combination of elements in a whole. Such an ubuntu would, as I see it, not only count for nothing but would constitute a negative concept. That is, it would be based on blocking out everything else that is contradictory, the absence of contradiction, and the avoidance of the complexities and messiness of everyday terra firma. This basis in absence and avoidance marks out this account of ubuntu not only as lacking completeness but also as a contentless, diffuse, ungraspable $u b u n t u$.

I have rejected as erroneous the popular view that European ethics are "individual" while African ethics are "communitarian". I argue that these conclusions are premised, firstly, on false and untenable dualities and, secondly, silence. Such silence must not be taken as definitive proof that Africans and African ethics are what scholars say they are. Also false 
is the account of freedoms that sanctions the conclusion that forms of freedom in the West are "individual" and those in Africa are "interdependent". By and large, what appears to be missing in these prevailing accounts of $u b u n t u$ is a strong preoccupation with seeing African persons as complex, expressive doing beings whose actions are never easily reducible to the limiting duality of "individual freedom" versus "interdependent freedom".

I neither consider "individual freedom" and "interdependent freedom" to be necessarily mutually exclusive nor do I see any value in seeing Africans as necessarily belonging to either of the two categories. What is it about trying to force Africans to fit, at every turn, these neat conceptual cages? There is no justification to limiting the categories one can posit nor to the memberships one can hold in these groups. It is not expressly clear, anyway, why one needs to clarify the problem through categories at all. We should be prepared to admit that there may even be other different kinds of ethical relations that may not be necessarily or roughly generalised under the catch-all category of ubuntu.

It occurs to me that the question of collisions, and, of course, the other questions that follow from it, would need to be adequately and sufficiently answered first before one assumes what an African morality or African ethics is. I insist that the ethical and unethical disrupt and construct one another in the true fashion of a turnstile or revolving door, making it difficult to sustain elegant distinctions. Good-will (and evil will) in human relations do not travel rectilinearly but bend, disperse, diffract, refract, scatter and travel in several (often unpleasant) directions.

We should not be abandoning the $u b u n t u$ baby every time we encounter a little unpleasantness, and only waving it about in fair weather. Rather, ubuntu should be an allweather, all-terrain critical philosophy. The frequent use of adverbs such as only to demarcate completely dependent relationships or selective readings is unproductive. I have, thus, favored and defended the view that Africans are more at home in voluntary mutual non- 
obligative relationships. At the heart of $u$ buntu should be indivisible individual informed choice, which is ranged against mindless prescription and the atavistic following of the herd.

I suspect that ubuntu is really just another word for good African citizenship, an (impure) ethics of good citizenship based on independent thought and action, good sense and informed choice in context. Insofar as far good citizenship makes for ethical living, it is possible to live ethically as long as one appreciates that only the most stupid actions are to be avoided. Anything that is not totally stupid may acceptably benefit oneself, one's family and one's community, and bring satisfaction and happiness. Somehow I suspect that the messier the relationship between persons, the more freedom, subjectivity and agency the individual has to shape their relationship with (or against) others in ways that increasingly suit and benefit each "free" individual involved in the relationship. Halfway between harmony and discord, protest and silence, horse and rider, individuality and interdependence, the real ubuntu may just be able to stand up. 


\section{NOTES}

1 At another level, shifting the terms from "umuntu" to, say, "inja" (dog), "imbongolo" (donkey), "ingulube" (pig), "inyoni" (bird), "isihlahla" (tree) or "umfula" (river) imply some interesting interpretations:

- Inja ibainja ngezinye izinja = a dog is a dog with other dogs

- Imbongolo ibaimbongolo ngezinye izimbongolo $=$ a donkey is a donkey with other donkeys

- Ingulube ibaingulube ngezinye izingulube = a pig is a pig with other pigs

- Inyoni ibainyoni ngezinye izinyoni = a bird is a bird with other birds

- Isihlahla siba yisihlahla ngezinye izihlahla = a tree is a tree with other trees

- Umfula ungumfula ngeminye imifula = a river is a river with other rivers

If a dog, donkey, pig, bird, tree, or river respectively is only a dog, donkey, pig, bird, tree or river with other dogs, donkeys, pigs, birds, trees or rivers, where does this leave the definition of ubuntu? Where and when does this "shared identity" begin to suggest that the quality that is being referred to is a gift?

What is being referred to in the examples given above could be that a tree (or dog, donkey, bird, pig, or river) is difficult to recognize or identify as a tree if there were only this one tree in the world. Rather, our prior knowledge and memory of many such trees is what allows a tree to become a tree to observers. One isolated tree on its own is not enough to leave behind a falsifiable identity of "tree", such that further acquaintances with different and more trees may be necessary in order for a picture of the identity "tree" to settle. In any case, the notion of a tree being a tree with other trees does not appear to contain much that should lead us to naturally impute "gift-ness" to trees. The equation of ubuntu with "gift", "harmony" and "good-will", it is clear, has not yet been sufficiently called into question.

2 Without this First Giver, there can be no ubuntu. This First Giver, however, could not have been human. This is because as a First Giver, he or she did not receive or acquire the gift of ubuntu. There would not have been anyone around to acquire the gift from or to give ubuntu to this First Giver. The illogicality comes thus: if Africans became persons from receiving ubuntu from a non-person, how could this be a gift? This gift is, therefore, essentially a non-gift. Its "gift-ness" is nullified and voided by the fact that the giver has no humanity, and is no human. How can a non-human give humanity? The voiding of the originary Giver leaves Africans without humanity.

A possible solution to the dilemma of the First Giver would be to abandon ourselves to the view that God gave the first gift of humanity to the first human being. Such a solution is a throwback to the story of Genesis, Prometheus and other creation/"giver" stories. The problem with such a solution, however, is that it seeks to explain everyday reality through a set of mythologies that ideally should not operate in the absence of interpretive disclaimers. The fixed definition of umuntu ngumuntu ngabantu as a set of relationships predetermined by and on "sharing" and "gifting" reduces Africans to vessels without agency, psychology, self or subjectivity. To say that an African's self is gifted to him or her is one way to deny that the African has a self. Such a view of humanity cannot allow, for instance, a conception of justice or freedom. Justice and freedom are not gifts, but are won and demanded. At the very 
least, Shutte's notion of "gift" needs to be clarified. In its present form, it mocks the humanity of Africans.

$3 \quad$ Such "freedom" protects the "free individual" from authorities and governments and includes such oft-touted "freedoms" as freedom of expression or media freedom.

$4 \quad$ Ramose (1999) even goes as far as interpreting Kwame Gyekye's assertion about the Akan people's subscription to a "tripartite conception of a person" (Gyekye, 1984 p.20) not only to mean that the Akan essentially hold an "individualistic (derivative) concept of person" (p.80) but also that the Akan are an exception to the African norm. The Akan concept of a person, says Ramose, is "the exception to the rule that for African traditional thought a person is primarily a wholeness" (p.80). Whether or not Gyekye was saying the Akan are "individualistic" is, however, not at all immediately or obviously clear 


\section{REFERENCES}

Bamford, R. (2007). Nietzsche and ubuntu. South African Journal of Philosophy, 26(1), 8597.

Broodryk, J. (2002). Ubuntu: Life lessons from Africa. Pretoria: Ubuntu School of Philosophy.

Bujo, B. (2001). Foundations of an African ethic: Beyond the universal claims of western morality (B. McNeil, Trans.). New York: Crossroad Publishing Company.

Cornell, D., \& van Marle, K. (2005). Exploring ubuntu: tentative reflections. African Human Rights Law Journal, 5, 195-220.

Cornell, D. (2011). Recognition of ubuntu. In D. Cornell \& N. Muvangua (Eds.). Ubuntu and the law: African ideals and postapartheid jurisprudence. New York: Fordham University Press

Cornell, D. (2012). Is there a difference that makes a difference between $u b u n t u$ and dignity. In S. Woolman \& D. Bilchitz (Eds.). Is this seat taken: Conversations at the bar, the bench and the academy about the South African constitution (221-239). Pretoria: Pretoria University Law Press.

Enslin, P., \& Horsthemke, K. (2004). Can ubuntu provide a model for citizenship education in African democracies? Comparative Education, 40, 545-58.

Freire, P. (1970[2005]). Pedagogy of the oppressed (M. B. Ramos, Trans.). New York: Continuum.

Gade, C.B.N. (2011). The historical development of the written discourses on ubuntu. South African Journal of Philosophy, 30(3), 303-329.

Gramsci, A. (1971). Selections from the prison notebooks of Antonio Gramsci (Q. Hoare, Ed.) (G.N. Smith, Trans.). London: Lawrence \& Wishart.

Gyekye, K. (1987). An essay on African philosophical thought. Cambridge: Cambridge University Press.

Gyekye, K. (1984). The Akan concept of person. In R.A. Wright (Ed.), African philosophy (pp.199-212). New York: University Press of America.

Letseka, M. (2012). In defence of ubuntu. Studies in Philosophy of Education, 31, 47-60.

Louw, D. (2001). Ubuntu and the challenges of multiculturalism in post-apartheid South Africa. Quest, 15, 15-36. 
Masolo, D.A. (2004). Western and African communitarianism: a comparison. In K. Wiredu (Ed.), Companion to African philosophy (pp. 483-98). Malden, MA Blackwell

Menkiti, I. (1984) Persons and Community in African Traditional Thought. In R.A. Wright (Ed.), African philosophy (pp.171-181). New York: University Press of America.

Metz, T. (2007). Toward an African moral philosophy. The Journal of Political Philosophy, 15(3), 321-341.

Metz, T., \& Gaie, J.B.R. (2010). The African ethic of ubuntu/botho: Implications for research on morality. Journal of Moral Education, 39(3), 273-290.

Metz, T. (2011). Ubuntu as a moral theory and human rights in South Africa. African Human Rights Law Journal, 11, 536-560.

Mokgoro, Y. (1998). Ubuntu and the law in South Africa. Potchefstroom Electronic Law Journal, 1, 1-11.

Mokgoro, Y., \& Woolman, S. (2012). Where dignity ends and ubuntu begins: An amplification of, as well as an identification of a tension in, Drucilla Cornell's thoughts. In S. Woolman \& D. Bilchitz (Eds.). Is this seat taken: Conversations at the bar, the bench and the academy about the South African constitution (221-239). Pretoria: Pretoria University Law Press.

Praeg, L. (2008). An answer to the question: What is ubuntu? South African Journal of Philosophy, 27(4), 367-385.

Ramose, M. (1999). African philosophy through ubuntu. Harare: Mond Books.

Ramose, M. (2003). The ethics of ubuntu. In P.H. Coetzee \& A.P.J. Roux (Eds.), Philosophy from Africa (324-30). Oxford: Oxford University Press.

Samkange, S., \& Samkange, T.M. (1980). Hunhuism or ubuntuism: A Zimbabwean indigenous political philosophy. Harare: Graham Publishing Company.

Shutte, A. (2001). Ubuntu: An ethic for the new South Africa. Pietermaritzburg: Cluster Publications.

Shutte, A. (2008). African ethics in a globalising world. In R. Nicolson (Ed.), Persons in Community: African ethics in a global culture, Durban: UKZN Press.

Tangwa, G., (1996). Bioethics: an African perspective. Bioethics, 10, 183-200.

Tolstoy, L. (1868-9) (2006). War and Peace (A. Briggs, Trans.). London: Penguin.

Tutu, D (1999). No future without forgiveness. New York: Random House.

Verhoef, H., \& Michel, C. (1997). Studying morality within the African context. Journal of Moral Education, 26, 389-407. 
Wiredu, K. (1996). Cultural universals and particulars: An African perspective. Bloomington: Indiana University Press. 